\title{
Bibliotecas universitárias e presença digital: estabelecimento de diretrizes para o uso de mídias sociais
}

Jorge Moisés Kroll do Prado

Doutorando em Ciência da Informação, Universidade Federal de Santa Catarina

Elisa Cristina Delfini Correa

Doutora em Sociologia Política, Universidade Federal de Santa Catarina .Professora no Departamento de Biblioteconomia e Gestão da Informação, Universidade do Estado de Santa Catarina

http://dx.doi.org/10.1590/1981-5344/2733

Apresenta diretrizes de uso de mídias sociais por bibliotecários em bibliotecas universitárias. Discute o contexto da sociedade contemporânea, fortemente marcada pela informação digital. Reflete também sobre o papel da biblioteca universitária aplicando o conceito de presença digital nesse contexto. Discute o perfil do bibliotecário enquanto ator no processo de inserção da biblioteca universitária no contexto digital. Apresenta resultados de pesquisa realizada no universo de bibliotecas universitárias de instituições públicas de ensino superior no Brasil. O percurso metodológico foi traçado por meio de uma pesquisa exploratória, documental e bibliográfica com análise de conteúdo aplicada aos documentos encontrados. Os dados foram coletados por meio de pesquisa bibliográfica e documental, além de levantamento em 40 sites de instituições internacionais. O texto finaliza apresentando sete diretrizes para o uso de mídias sociais em bibliotecas universitárias de modo a fomentar uma presença digital mais efetiva e relevante.

Palavras-chave: Bibliotecas universitárias; Mídias sociais; Presença digital; Mídias sociais - diretrizes de uso. 


\title{
University libraries and digital presence: guidelines for the use of social media
}

\begin{abstract}
This article presents guidelines of use of social media by librarians in university libraries. It argues the context of the contemporary society, strongly marked by the digital information. It reflects also on the role of the university library applying the concept of digital presence in this context. It argues the profile of librarian while actor in the process of insertion of the university library in the digital context. It presents resulted of investigation made in the universe of university libraries of college public institutions in Brazil. The methodological route was traced by an exploratory, documentary and bibliographical investigation with content analysis applied to documents found. Data were collected through bibliographic and documentary research, and survey in 40 sites of international institutions. The article concludes by presenting seven guidelines for the use of social media in university libraries in order to foster a more effective and relevant digital presence.
\end{abstract}

Keywords: University libraries; Social media; Digital presence; Social media - usage guidelines.

Recebido em 04.03.2016 Aceito em 18.05.2016

\section{Introdução}

Estão bastante presentes na literatura científica de diferentes áreas do conhecimento, reflexões que buscam expressar os contextos sociais através dos tempos. Baseiam-se em discursos sobre transformações econômicas, políticas e socioculturais que trazem algumas nomenclaturas como "sociedade pós-moderna", "sociedade da informação", "modernidade líquida", "sociedade do conhecimento". Para compreendermos melhor, é importante destacar alguns autores e suas respectivas contribuições.

Após seus estudos acerca das estatísticas de empregos nos Estados Unidos, onde pode notar um crescimento expressivo no setor de serviços, Daniel Bell vem a caracterizar a sociedade contemporânea como sendo um período pós-industrial, onde a ciência e a técnica atuam com destaque (NUNES, 2014; BELL, 1974). Um tempo marcado pelas máquinas e pela alta produtividade passa a dar lugar aos métodos, à qualidade. 
Quando a reflexão é dirigida para questões sobre tempo e espaço, o estudo do sociólogo Zygmunt Bauman torna-se pertinente. Marcada por uma fluidez nas relações pessoais e de trabalho, esta sociedade contemporânea recebe o sinônimo de "modernidade líquida". As concepções sobre o que entendemos a respeito de tempo e de como agimos em determinado espaço, são pensadas agora de maneira muito mais frágil, pouco limitada e muito mais rápida (BAUMAN, 2011).

De modo semelhante, este atual contexto social configura-se para Anthony Giddens como "alta modernidade", , onde as transformações nas características fundamentais se acentuam. É uma definição imprevisível, visto que "as consequências desestabilizadoras [da modernidade] se combinam com a circularidade de seu caráter reflexivo para formar um universo de eventos onde o risco e o acaso assumem um novo caráter" (GIDDENS, 1991, p. 175).

Nas reflexões destes autores supracitados, inferem-se alguns pontos em comum, como a presença atuante da tecnologia, que consegue delinear novos laços sociais. Seu papel é preponderante para um desenvolvimento econômico, político e cultural da sociedade ao longo das décadas. Castells (2002) afirma que é difícil conseguir traçar a história das transformações sociais que foram proporcionadas, uma vez que ainda estamos vivendo este momento de mudanças.

Os elementos "informação" e "conhecimento", que receberam tanto destaque nos trabalhos de alguns sociólogos que se dedicaram a estudar a sociedade contemporânea, são para Castells (2005) facilmente identificáveis ao longo do tempo, sempre estiveram presentes. Para o autor, a novidade está nas redes de tecnologias microeletrônicas, que servem como um impulso para a organização e construção social de uma sociedade em rede e se apresentam como "uma estrutura social [...] operada por tecnologias de comunicação e informação [...] e em redes digitais de computadores que geram, processam e distribuem informação a partir de conhecimento acumulado nos nós dessas redes" (CASTELLS, 2005, p. 20).

Além de relações humanas criadas com mais facilidade e de uma economia com altas taxas de crescimento por conta de novas formas de se organizar, produzir e distribuir, esta sociedade em rede é fortemente marcada pela comunicação. São tendências desta característica o aglomerado de mídias (TV, rádio, imprensa escrita), os ambientes digitais e interativos com audiências segmentadas por interesses e diferentes objetivos, mas principalmente a comunicação de massa difundida por toda a Internet a partir das mídias sociais (CASTELLS, 2005).

Desenvolve-se, assim, um cenário favorável para a construção de comunidades virtuais, com indivíduos que criam, se relacionam, informam, disseminam, trabalham, estudam, sem a limitação de espaço e de tempo. "Qualquer política, estratégia, projeto humano, tem que partir dessa base", salienta Castells (2005, p. 26).

Esta necessidade já é iminente para diferentes organizações. Cada vez mais são criados espaços e oportunidades que propiciem uma integração com esta sociedade em rede. $O$ que antes se delimitava 
exclusivamente ao mundo offline, hoje poderá perder um importante espaço de atuação se desconsiderar sua presença online. Uma presença em ambientes digitais precisa ser criada e fortalecida tanto como vantagem competitiva, como uma adequação.

Este cenário digital envolve igualmente as bibliotecas, que também devem construir uma presença relevante no ciberespaço, independente de sua tipologia. O presente artigo, no entanto, dedica-se ao universo das bibliotecas universitárias da rede pública de ensino (federais, estaduais e institutos federais) e o estabelecimento de sua presença digital. Questiona-se como problema de pesquisa: Que diretrizes os bibliotecários brasileiros de bibliotecas universitárias podem seguir para atuar de forma a promover a interatividade e participação nas mídias sociais?

Para atingir esse objetivo, o presente estudo se propôs a apresentar diretrizes de uso de mídias sociais que possam orientar o trabalho do bibliotecário universitário, fundamentando a presença digital no espaço das bibliotecas universitárias. Com base nesses propósitos, foi realizada uma análise comparativa de manuais que orientam o uso de mídias sociais, buscando construir o conjunto de diretrizes aqui apresentado.

Esta contribuição científica justifica-se pelo fato da necessidade de um documento teórico-metodológico onde as bibliotecas sejam o seu foco, já que o contexto da sociedade em rede e do crescente uso de mídias sociais pode se constituir em uma importante variável na construção de um novo panorama para as bibliotecas do século XXI.

\section{Presença digital de bibliotecas universitárias}

A presença digital de qualquer organização é efetiva quando se aliam suas ferramentas, espaços e estratégias das quais dispõem. Ela é criada e engajada principalmente pelas mídias sociais, que são uma das mais importantes ferramentas da web 2.0.

Imaginada por Tim Berners-Lee como um espaço de informação com livre acesso, cooperativo e intuitivo, a web 2.0, também chamada de web social, é centrada no indivíduo (VIEIRA, 2013; BLATTMANN; SILVA, 2007). Com repercussões sociais que potencializam o coletivo, surgem neste contexto as mídias sociais. Telles (2010) afirma que elas são ferramentas online utilizadas para divulgar conteúdo e permitir alguma relação com outras pessoas. Já Recuero, Bastos e Zago (2015) afirmam que uma mídia social é o conjunto de ações de centenas de milhares de redes com visualização e reprodução de informações.

Web 2.0 e mídias sociais se apresentam como um grande desafio e novidade, exigindo que as organizações adequassem seus produtos e serviços para este contexto. O mesmo se atribui às bibliotecas, já que agora a relação com a informação deixou de ser somente de acesso, mas também de interação. Maness (2007, p. 44) afirma que com a "aplicação de interação, colaboração e tecnologias multimídia baseadas em web para serviços e coleções", tem-se uma biblioteca 2.0.

Assim, fica evidente a necessidade de se criar e manter uma presença digital que, conceituando de forma muito básica, significa 
"existência de algo (seres humanos, marcas, empresas, coisas, etc.) no ambiente digital" (GABRIEL, 2010, p. 249). Ampliando o conceito, significa também uma presença que ofereça produtos e serviços de informação que atendam às necessidades da comunidade onde atua.

O conceito aplica-se ao universo das bibliotecas em geral, contudo, de forma mais específica, aplica-se com propriedade às bibliotecas universitárias levando em consideração seu importante papel na construção do conhecimento científico e seu envolvimento com a pesquisa, o ensino e a extensão. Estar presente no mundo digital representa a possibilidade de tornar a biblioteca conhecida, criar e manter redes de comunicação e informação, ampliar seu espectro de inserção na sociedade e atingir um público ainda maior para além de suas paredes.

Por isso, faz-se necessário reunir esforços para trazer conteúdos digitais relevantes para a sua comunidade. Sua presença digital será constituída de seus produtos e serviços de informação pautados pela web 2.0, levando em consideração as necessidades e a participação da comunidade envolvida, disseminando e criando conteúdo relevante e engajador via mídias sociais.

Esta iniciativa resulta na característica de "um grupo pioneiro de organizações que aceitam as regras do mundo 2.0" (TERRA, 2011, p. 145), que está preparado para atuar em ambiente digital. Há quatro fases para que a presença digital possa ser alcançada, conforme Strutzel (2015).

A primeira delas é a fase da existência, que no ambiente das bibliotecas universitárias não pode se limitar, por exemplo, à disseminação seletiva da informação. É fundamental que haja um espaço em que a comunidade possa interagir com esse serviço. Para que isso aconteça, antes de ir ao ambiente online, a equipe da biblioteca precisa estar ambientada com a web, conhecer as ferramentas e as possibilidades de uso que elas podem propiciar.

Os primeiros contatos e resultados com as ações de planejamento, acontecem na fase da atração, que é a segunda para um modelo satisfatório de presença digital. Estando todas as estratégias planejadas, com delimitação de recursos (financeiros, humanos), de conteúdo (mídias utilizadas, tipo de linguagem) e de fluxo de gestão (periodicidade, responsabilidades e monitoramento), esta fase poderá ser alcançada através da interação propagada com a comunidade (STRUTZEL, 2015).

Já na fase de relacionamento, é necessário manter um acompanhamento bastante próximo com as estratégias delimitadas na fase anterior, a fim de identificar a necessidade de um novo posicionamento estratégico ou mesmo de atualização. Strutzel (2015, p. 90) afirma que é "imprescindível um acompanhamento muito próximo do feedback para cada ação ou conteúdo compartilhado", em outras palavras, é acompanhar e dar o devido retorno à interação alcançada.

Por último, após as demais fases serem bem executadas, há a fase de engajamento. É nela que a comunidade acompanha ativamente o que a biblioteca compartilha em mídias sociais, mantendo um vínculo de 
relacionamento digital. Para que isso aconteça, é importante conhecer como o seu público se engaja e apresentar serviços e produtos relevantes.

Uma biblioteca universitária com uma presença digital forte e atuante, é propensa a apresentar melhores resultados na comunidade onde atua. Para que isso aconteça, é importante trazer a ressalva de que um planejamento é necessário, conhecendo tanto o potencial da equipe da biblioteca (que será responsável por alavancar e manter esta presença), como a comunidade onde ela atua.

Neste contexto de sociedade em rede e da importância em ser presente digitalmente, buscou-se criar diretrizes para o uso de mídias sociais em bibliotecas universitárias. Para que isso fosse alcançado, alguns procedimentos metodológicos foram utilizados e são descritos em seguida.

\section{Procedimentos metodológicos e discussão dos resultados}

Para um maior conhecimento do universo das bibliotecas universitárias brasileiras públicas (universidades federais e estaduais e institutos federais de educação), procedeu-se uma pesquisa a partir da plataforma do e-MEC (sistema eletrônico de acompanhamento dos processos que regulam a educação superior no Brasil), na qual foram listadas 141 bibliotecas $^{1}$ a fim de encontrar diretrizes sobre o uso das mídias sociais.

Ainda como parte desse levantamento, a partir do Scimago Institutions Ranking (SIR), foram listadas 40 instituições dos idiomas Inglês e Espanhol, também com o intuito de encontrar bibliotecas que fizessem uso de diretrizes para sua atuação nas mídias sociais. Optou-se pelo SIR por conta dos indicadores que ele apresenta que são focados na visibilidade web.

Tanto nas bibliotecas brasileiras, como nas internacionais, o propósito foi o de buscar a presença de algum manual que traçasse diretrizes para o uso das mídias sociais. Com o resultado desta busca, seria possível aplicar a metodologia de análise de conteúdo de Bardin (2011) em cada um dos documentos recuperados a fim de selecionar os critérios que colaborariam com a construção das diretrizes propostas nesta pesquisa.

A apresentação e análise dos dados destes levantamentos são apresentados na seção a seguir, bem como a análise de conteúdo dos manuais com diretrizes de mídias sociais.

\subsection{Apresentação e análise dos dados}

No âmbito nacional, com a lista das 141 bibliotecas universitárias, a primeira etapa foi a de visitar cada um dos sites para encontrar alguma menção a respeito do uso de mídias sociais. Importante pontuar aqui a dificuldade em encontrar a página web da biblioteca dentro da página da

\footnotetext{
${ }^{1}$ Levantamento realizado em 6 de outubro de 2014.
} 
instituição a qual ela pertence, raramente se encontra em destaque o link de acesso.

Na página da biblioteca foi observado se havia alguma menção a mídias sociais, seja através de links ou ícones, e também se havia algum documento com diretrizes de uso destas mídias. Os resultados deste primeiro levantamento são apresentados na Tabela 1:

Tabela 1 - Panorama das bibliotecas universitárias brasileiras nas mídias sociais

\section{BIBLIOTECAS DE INSTITUTOS FEDERAIS}

\begin{tabular}{l|c}
\hline \hline Número de bibliotecas & 40 \\
\hline Quantas possuem diretrizes de mídias sociais? & 00 \\
\hline Quantas estão no Facebook? & 18 \\
\hline Quantas estão no Twitter? & 09 \\
\hline Quantas estão em outras mídias? & 01 \\
\hline Que outras mídias foram identificadas? & Blog \\
\hline Quantas não estão presentes em nenhuma mídia social? & 19 \\
\hline
\end{tabular}

BIBLIOTECAS DE UNIVERSIDADES ESTADUAIS

\begin{tabular}{l|c}
\hline \hline Número de bibliotecas & 38 \\
\hline Quantas possuem diretrizes de mídias sociais? & 00 \\
\hline Quantas estão no Facebook? & 13 \\
\hline Quantas estão no Twitter? & 12 \\
\hline Que outras mídias foram identificadas? & $\begin{array}{c}\text { Blog, YouTube, FlickR, SlideShare e } \\
\text { Google+ }\end{array}$ \\
\hline Quantas não estão presentes em nenhuma mídia social? & 15 \\
\hline
\end{tabular}

\section{BIBLIOTECAS DE UNIVERSIDADES FEDERAIS}

\begin{tabular}{l|c}
\hline Número de bibliotecas & 63 \\
\hline Quantas possuem diretrizes de mídias sociais? & 00 \\
\hline Quantas estão no Facebook? & 47 \\
\hline Quantas estão no Twitter? & 36 \\
\hline Que outras mídias foram identificadas? & Blog, YouTube, Google+ e Issuu \\
\hline Quantas não estão presentes em nenhuma mídia social? & 16 \\
\hline
\end{tabular}

Fonte: Elaborado pelos autores (2015). 
Com o propósito de benchmarking e de também aumentar as possibilidades de encontrar diretrizes que pudessem ser analisadas posteriormente, o levantamento se deu em 40 instituições internacionais (20 do idioma Inglês e 20 do Espanhol). Esta seleção compõem as melhores colocadas do ranking Scimago com os indicadores Website Size e High Education.

A Tabela 2 apresenta os dados encontrados das visitas efetuadas a cada um dos sites destas instituições:

Tabela 2 - Panorama das bibliotecas universitárias internacionais nas mídias sociais

\section{BIBLIOTECAS DO IDIOMA INGLÊS}

\begin{tabular}{l|c}
\hline \hline Número de bibliotecas & 20 \\
\hline Quantas possuem diretrizes de mídias sociais? & 01 \\
\hline Quantas estão no Facebook? & 20 \\
\hline Quantas estão no Twitter? & 18 \\
\hline Que outras mídias foram identificadas? & $\begin{array}{c}\text { YouTube, FlickR, Instagram, Blog, } \\
\text { Pinterest, TumblR, Zazzle, Google } \\
\text { Scholar, iTunesU, Vimeo e } \\
\text { Soundclound }\end{array}$ \\
\hline Quantas não estão presentes em nenhuma outra mídia social? & \begin{tabular}{c} 
05 \\
\hline
\end{tabular}
\end{tabular}

BIBLIOTECAS DO IDIOMA ESPANHOL

\begin{tabular}{l|c}
\hline \hline Número de bibliotecas & 20 \\
\hline Quantas possuem diretrizes de mídias sociais? & 04 \\
\hline Quantas estão no Facebook? & 20 \\
\hline Quantas estão no Twitter? & 17 \\
\hline Que outras mídias foram identificadas? & $\begin{array}{c}\text { YouTube, Pinterest, FlickR, Blog, } \\
\text { Issuu, SlideShare, Google+, Tuenti, } \\
\text { Prezi, Foursquare, Storify, Klout, } \\
\text { Diigo, Gravatar, Bitly }\end{array}$ \\
\hline Quantas não estão presentes em nenhuma outra mídia social? & \begin{tabular}{c} 
07 \\
\hline
\end{tabular}
\end{tabular}

Fonte: Elaborado pelos autores (2015).

As tabelas demonstram a discrepância existente entre os dois panoramas, a começar pelo número de bibliotecas que estão no Facebook e Twitter (duas das mais utilizadas mídias sociais no mundo), o número de documentos com diretrizes encontrados e rol de outras mídias sociais onde as bibliotecas vêm atuando. 
Concluindo esta primeira etapa metodológica, os cinco manuais com diretrizes de uso de mídias sociais por bibliotecas universitárias que foram encontrados são das seguintes instituições: University of Virginia, Universidade de Santiago de Compostela, Universidad de Chile, Universidad Carlos III de Madrid e Universidad de Sevilla.

A próxima etapa foi aplicar a análise de conteúdo de Bardin (2011) em cada um dos manuais com o propósito de elencar um rol de diretrizes de uso de mídias sociais.

\subsection{Análise de conteúdo dos documentos encontrados}

A metodologia de análise de conteúdo é "um conjunto de técnicas de análise das comunicações que utiliza procedimentos sistemáticos e objetivos de descrição do conteúdo das mensagens" (BARDIN, 2011, p. 44). Com ela, foi possível construir uma lista de diretrizes para o uso de mídias sociais em bibliotecas conforme alguns elementos já encontrados nos 05 manuais levantados. A organização desta análise dividiu-se nos três polos cronológicos propostos por Bardin (2011): pré-análise, exploração do material e tratamento dos resultados com inferência e interpretação.

Como categorias de análise, foram utilizados os seguintes termos: Planejamento; Aspectos comportamentais e sociais; Aspectos éticos e jurídicos; Linguagens e tipos de conteúdo; Monitoramento e métricas e Gestão de crises. Desta forma, foi possível reunir unidades de análise dos cinco manuais para se evidenciar os aspectos mais relevantes ao propor diretrizes para as bibliotecas universitárias brasileiras no uso de mídias sociais. O Quadro 1 contempla estes dados:

Quadro 1 - Análises de conteúdo dos manuais de mídias sociais

\begin{tabular}{c|l}
\hline CATEGORIAS DE DIRETRIZES & \multicolumn{1}{c}{ UNIDADES DE ANÁLISE } \\
\hline \hline \multirow{2}{*}{ Planejamento } & - Gestão participativa \\
& - Missão e valores \\
- Plano de postagens & - Uso de diferentes canais para determinadas finalidades \\
& - Marketing \\
& - Objetivos e possibilidades \\
& - Serviços e produtos na web \\
& - Parceria com equipes de profissionais de outras áreas \\
& (Design, Comunicação, Marketing) \\
\hline Aspectos comportamentais e sociais & - Público real \\
& - Público potencial \\
& - Estabelecer um diálogo com o público \\
& - Publicações que propiciem o engajamento \\
\hline Aspectos éticos e jurídicos & - Direitos legais \\
& - Veracidade das informações publicadas \\
& - Indicação das fontes \\
& - Responsabilidade de autoria e de serviços prestados \\
\hline
\end{tabular}




\begin{tabular}{|c|c|}
\hline Linguagens e tipos de conteúdo & $\begin{array}{l}\text { - Efetividade na comunicação } \\
\text { - Mensagens claras } \\
\text { - Qualidade no uso das mídias sociais } \\
\text { - Uso de ferramentas para gestão de conteúdo } \\
\text { - Linguagem sem regionalismos e não tão informal } \\
\text { - Não levantar conteúdos opinativos sobre temas polêmicos }\end{array}$ \\
\hline Monitoramento e métricas & $\begin{array}{l}\text { - Acompanhamento periódico da interação dos usuários } \\
\text { - Relatórios de evolução do uso das mídias sociais } \\
\text { - Uso de ferramentas para monitoramento }\end{array}$ \\
\hline Gestão de crises & $\begin{array}{l}\text { - Respostas rápidas aos questionamentos } \\
\text { - Prever crises conforme tonalidade e conteúdo de } \\
\text { comentários } \\
\text { - Cordialidade nas respostas } \\
\text { - Exclusão de comentários ofensivos } \\
\text { - Moderação de comentários }\end{array}$ \\
\hline
\end{tabular}

Fonte: Elaborado pelos autores (2015).

Todos os manuais analisados possuíam muitas semelhanças entre si, embora alguns se limitaram a explicar como o bibliotecário cria uma conta em mídia social, por exemplo. Este elemento foi descartado, pois acaba tornando a diretriz passível de constantes atualizações, uma vez que o modo de se criar uma conta em determinada mídia social acabe por sofrer mudanças com razoável frequência.

Alguns dos manuais se preocuparam bastante com o uso da marca da biblioteca e da instituição a qual está vinculada, principalmente quanto à disposição gráfica em páginas online (site e perfis em mídias sociais). É uma questão importante, já que será a principal maneira que a comunidade reconhecerá a biblioteca, além de também poder transmitir uma mensagem (como seu slogan por exemplo).

Evidencia-se também o fator de planejamento apresentado, que sustenta e norteia a ação das bibliotecas nas mídias sociais, permeando todas as fases para a construção de uma presença digital. Manter a existência de forma a atrair a comunidade, relacionando-se com ela e engajando-a com seu conteúdo, necessita que o bibliotecário planeje suas ações.

Em relação as quatro fases da presença digital apresentadas na seção 2 com o quadro 1 da análise de conteúdo dos manuais de mídias sociais, podemos destacar os seguintes aspectos:

- Fase 1: Existência: contemplará todas as categorias de diretrizes, pois cada uma delas são fatores determinantes para que se mantenha a existência de uma presença em mídias sociais, embora a categoria de diretriz "Planejamento" receba maior destaque. Além disso, é a fase mais introdutória de todas, pois necessita uma ambientação por parte dos bibliotecários a respeito dos espaços online que serão utilizados.

- Fase 2: Atração: voltada principalmente para as seguintes categorias de diretrizes: "Aspectos comportamentais e sociais" e "Linguagens e tipos de conteúdo". É a fase onde se constituirá a vinda da comunidade para os espaços online da biblioteca e o modo como a 
"fidelizará", garantirá a audiência. Para que isso seja possível, é importante conhecer os aspectos de comportamento para que se construa um estilo de linguagem e tipo de conteúdo a se disseminar.

- Fase 3: Relacionamento: uma vez que se conquiste o público, é necessário mantê-lo, relacionar-se com ele. As categorias de diretriz "Aspectos comportamentais e sociais", "Aspectos éticos e jurídicos", "Linguagens e tipos de conteúdo" e "Monitoramento e métricas" são fundamentais para esta fase. É fundamental uma atuação em mídias sociais que acompanhe o comportamento da comunidade, com conteúdo entregue de forma ética em mesma linguagem e com monitoramento constante a fim de atender, responder e interagir com o público.

- Fase 4: Engajamento: esta última fase praticamente garante a continuidade da primeira, pois reflete toda a circulação e apropriação da informação nas mídias sociais da biblioteca universitária. Assim, todas as categorias de diretrizes supracitadas nas fases anteriores são importantes para esta fase, além da "Gestão de crises", que ajudará a evitar problemas que denigram a presença digital da biblioteca.

\section{Diretrizes para o uso de mídias sociais}

A importância de se ter diretrizes de uso de mídias sociais dentro de uma biblioteca dá-se pela consistência na atuação focada numa presença digital forte e segmentada com base em seu público alvo. Logo, elas precisam integralizar a produção, disseminação, interação e monitoramento de conteúdo conforme um planejamento.

Assim, a primeira das diretrizes diz respeito ao Planejamento. Nesta primeira etapa é importante apresentar quais os objetivos que se quer alcançar com o uso das mídias sociais e quais os recursos humanos e financeiros que a biblioteca universitária dispõe. Um texto breve e claro é o suficiente para contextualizar tanto o leitor como a equipe da biblioteca envolvida com a tarefa.

Alguns questionamentos de apoio podem facilitar na redação deste texto, como:

- Onde?: tipo da biblioteca, que público atende, seu objetivo em relação com a universidade, sua missão e seus valores;

- Por quê?: quais os objetivos e metas da biblioteca estar nas mídias sociais. Aqui você pode se limitar a algo menor, como alcançar um número $X$ de novas curtidas na página do Facebook, ou algo maior, como criar serviços e produtos com base no excedente cognitivo dos envolvidos na universidade;

- Como?: quais mídias serão utilizadas e a respectiva periodicidade de postagens em cada uma delas. Lembrar de sempre atuar onde a comunidade está presente e respeitar a dinâmica de cada mídia social (textos longos para blogs ao invés de Facebook, por exemplo). Se houver 
um número grande de espaços que a biblioteca irá utilizar, recomenda-se indicar qual o propósito de cada uma junto do planejamento da biblioteca;

- Quando?: como a dinâmica informacional em rede é muito rápida, é importante apresentar uma data de validade ou período de atualização das diretrizes adotadas pela biblioteca;

- Quem?: profissionais envolvidos com as mídias sociais da biblioteca e quais suas respectivas tarefas.

A segunda das diretrizes versa sobre os Aspectos sociais e comportamentais, que são fundamentais para compreender as interações entre biblioteca e comunidade. Há algumas maneiras para se fazer isso, a começar pelo tradicional estudo de usuário. Com perguntas como "quanto tempo passa online?", "que tipo de informação busca nas mídias sociais?", "qual horário costuma acessar as mídias sociais" e outras semelhantes buscando traçar estes detalhes.

A netnografia, que busca tratar dos atores envolvidos no ciberespaço (ROCHA; MONTARDO, 2005), também é uma maneira para se trabalhar com esta diretriz. Pode ser realizada de maneira manual ou automatizada com a análise de comentários e postagens.

Uma das melhores formas de conhecer a sua comunidade e seus aspectos sociais e comportamentais, é o próprio uso das mídias sociais. Apesar de levar um pouco mais de tempo, quando atento às interações e monitoramento do fluxo de acessos, o bibliotecário será mais estratégico ao gerar conteúdo.

Toda a criação de postagens, em qualquer mídia social, vai ao encontro da terceira diretriz: Aspectos éticos e jurídicos. O bibliotecário precisa estar atento quanto a presença digital de sua biblioteca a fim de evitar crimes cibernéticos (uso inapropriado de imagem e texto, plágio, direito autoral, invasão de privacidade e outros).

A primeira das recomendações a se pontuar nesta diretriz é que o bibliotecário conheça os termos de uso de cada mídia social que resolva colocar a sua biblioteca. É neste documento que ele encontrará seus direitos, deveres, limitações e imposições. Já uma segunda recomendação é ter conhecimento sobre a legislação brasileira acerca da Internet, que apesar de ainda caminhar a passos lentos no Brasil, é o que respalda qualquer tomada de decisão num problema jurídico.

Por mais que a Internet cause uma impressão de que tudo seja livre e acessível, o bibliotecário precisa se garantir com o conteúdo que cria e compartilha. No uso de imagens, por exemplo, é recomendável que se faça o uso de bancos de imagens com direitos já garantidos.

A quarta diretriz aborda as Linguagens e tipos de conteúdo com os quais o bibliotecário irá trabalhar e assim construir a imagem da biblioteca. Textos muito rebuscados, ou pelo contrário, muito informais, podem ser pouco aceitos pela comunidade, portanto, trazer o mesmo tom e linguagem que seu público utiliza é fundamental. 
Sobre o conteúdo, quanto mais valor embutido ele tiver, melhor. É isto que acaba por caracterizar uma boa página online, garantindo que sempre haja uma boa interação. Muito mais que somente informar, o conteúdo precisa engajar o público, e isso é feito desde o modo como o texto é redigido, com algumas técnicas já concebidas.

Uma delas é a do modelo AIDA (sigla para Atenção, Interesse, Desejo e Ação), criado há mais de 100 anos por Elmo Lewis e que tem por objetivo compreender o comportamento de um indivíduo em relação ao objeto (seja ele físico ou abstrato) (SERRANO, 2006).

- Atenção: postagens com chamadas ou títulos mais atrativos tem maior visibilidade ou então que façam uso de imagens que além de expressar visualmente o conteúdo, sejam atrativas ou criativas. Destaque também para o tamanho dos textos, pois dependendo da mídia, um texto muito longo poderá não ser lido.

- Interesse: Tendo despertado a atenção, logo em seguida há ponto do interesse, ou seja, que tenha um contexto. Exemplo: uma biblioteca setorial na área de Comunicação ao postar algo sobre Agronomia, não surtirá efeito, já que o público é de outra área de conhecimento.

- Desejo: todas as novas propostas de serviços e produtos informacionais nas mídias sociais devem ser de desejo e necessidade da comunidade.

- Ação: é quando o conteúdo consegue fazer o público interagir com a página, dando sua opinião, participando e até mesmo construindo algo em meio digital.

Uma vez que a biblioteca consiga identificar qual a melhor linguagem para utilizar em suas mídias sociais, tenha compreendido os aspectos sociais e comportamentais de sua comunidade e venha trabalhando legal e eticamente com seus conteúdos, chega-se ao momento da quinta diretriz: Monitoramento e métricas.

Esta etapa costuma ser esquecida por quem trabalha com mídias sociais nas bibliotecas, deixando de acompanhar depois de um tempo as interações com o conteúdo publicado. Acompanhar a percepção do público é peça-chave inclusive para entender melhor seus aspectos comportamentais em rede. Além disso, o monitoramento é a principal ferramenta para avaliar o uso das mídias sociais conforme o planejamento proposto.

Silva (2012) destaca que esta tarefa pode ser feita manualmente ou por meio de softwares gratuitos ou pagos. Algumas mídias sociais apresentam em sua área de administração relatórios próprios que contribuem para o monitoramento.

Para saber o que monitorar, é necessário elencar algumas métricas que contribuam para quantificar fenômenos, causas e até mesmo projetar 
resultados (SILVA, 2013). Talk2 (2013), empresa especializada neste ramo, apresenta três tipos que podem ser trabalhados:

- Métricas de abrangência: quantas novas curtidas? quantos novos seguidores?

- Métricas de conversão: quantas pessoas interagiram com um produto? quantas preencheram um formulário online de seu site?

- Métricas por afinidade: quantas pessoas falam bem (e mal) da biblioteca? quais contextos a biblioteca é mencionada?

Com o acompanhamento periódico destas métricas, bem como a criação de relatórios para finalidade avaliativa, será possível saber se os objetivos propostos previamente no planejamento estão sendo alcançados, além de evitar que surjam crises.

A sexta diretriz é justamente sobre este elemento: Gestão de crises. Qualquer dano ou ameaça à biblioteca por meio de mídias sociais caracteriza-se como uma crise (GABRIEL, 2010). Ela pode ser uma reclamação sobre um serviço prestado pela biblioteca ou mesmo uma manifestação rude com opinião contrária a alguma postagem.

Barefoot e Szabo (2010) afirmam que uma boa gestão de crises envolve muito planejamento de como o conteúdo será publicado e monitorado posteriormente. Os autores afirmam também que é necessário manter uma postura honesta e franca com posicionamentos adversos, além de manter clareza na redação a fim de evitar interpretação dúbia.

A sétima e última diretriz destaca a importância de se avaliar tudo o que foi feito: Cronograma avaliativo. É o momento de observar se os objetivos delimitados no planejamento foram alcançados e de traçar novos, de verificar se as mídias sociais escolhidas para promover a presença digital da biblioteca foram bem utilizadas e chegaram ao seu propósito, de resgatar os relatórios do monitoramento para analisar as interações. Esta diretriz é elementar para uma boa presença digital da sua biblioteca.

Para facilitar a compreensão e uso por bibliotecas universitárias e por estudos avaliativos desta natureza, apresentamos um quadro sinótico que resume as diretrizes de uso de mídias sociais na Figura 1. 
Figura 1 - Diretrizes de uso de mídias sociais para bibliotecas universitárias

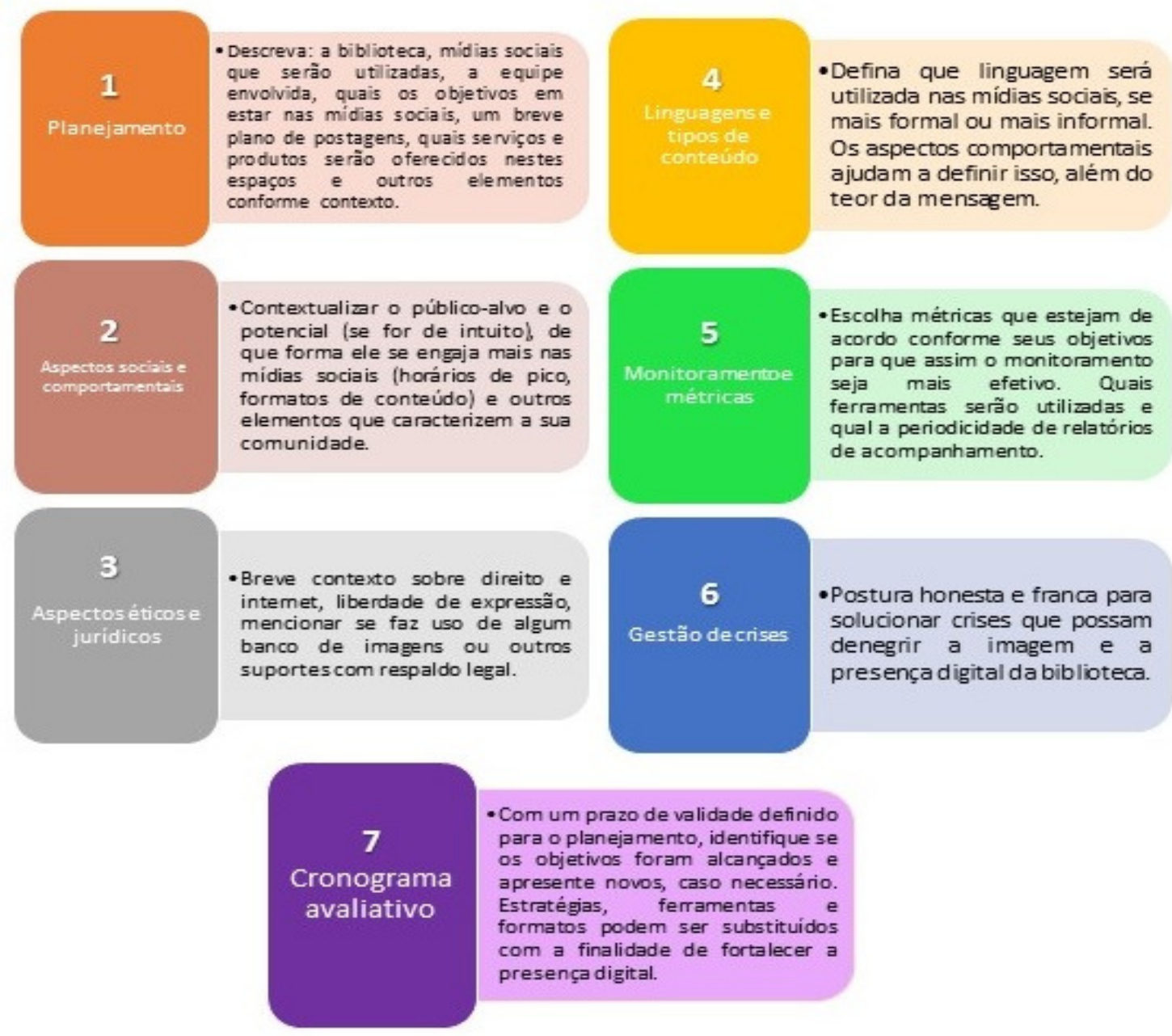

Fonte: Elaborado pelos autores (2015).

\section{Considerações finais}

A sociedade em rede demonstra ser um espaço que proporciona fluidez e poucas limitações nas trocas existentes nas relações humanas. Com as tecnologias da informação e comunicação, principalmente as mídias sociais, surge um contexto que remodela as atividades dos indivíduos e das organizações.

O panorama das bibliotecas universitárias públicas brasileiras nas mídias sociais é um excelente tema de estudo, com diferentes problemas de pesquisa a ser levantados. Mesmo com o discurso de "disseminar a informação" tão presente na profissão, surpreende o fato de que cinquenta, das 141 bibliotecas do levantamento desta pesquisa, não estejam em nenhuma mídia social.

Desta forma, este artigo buscou apresentar diretrizes para o uso de mídias sociais por bibliotecários universitários, como uma forma de auxiliar na construção e manutenção de sua presença digital. Elas versam sobre boas práticas, elementos comuns para se estabelecer uma boa 
comunicação, sem se preocupar com limitações e detalhes técnicos de cada mídia social.

Embora ambientadas para as bibliotecas universitárias, bibliotecários de outras tipologias, conforme suas realidades e necessidades, poderão utilizar as mesmas diretrizes.

Espera-se que as diretrizes aqui apresentadas possam auxiliar no trabalho do bibliotecário universitário, de modo que proporcione novos serviços e produtos, legitimando seu papel social de biblioteca como espaço disseminador de informação e de construção de novos conhecimentos.

\section{Referências}

BARDIN, L. Análise de conteúdo. São Paulo: Edições 70, 2011.

BAREFOOT, D; SZABO, J. Manual de marketing em mídias sociais. São Paulo: Novatec, 2010.

BAUMAN, Z. Modernidade líquida. Rio de Janeiro: Zahar, 2011.

BELL, D. O advento da sociedade pós-industrial. São Paulo: Cultrix, 1974.

BLATTMAN, U; SILVA, F. C. C. da. Colaboração e interação na web 2.0 e biblioteca 2.0. Rev. ACB: Biblioteconomia em Santa Catarina, Florianópolis, v. 12, n. 2, 2007.

CASTELLS, M. A sociedade em rede. 6. ed. São Paulo: Paz e Terra, 2002.

CASTELLS, M. A sociedade em rede: do conhecimento à política. In: CASTELLS, M.; CARDOSO, G. (Orgs.). A sociedade em rede: do conhecimento à acção política. Lisboa: Imprensa Nacional, 2005.

GABRIEL, M. Marketing na era digital: conceitos, plataformas e estratégias. São Paulo: Novatec, 2010.

GIDDENS, A. As consequências da modernidade. São Paulo: Editora UNESP, 1991.

MANESS, J. M. Teoria da biblioteca 2.0: web 2.0 e suas implicações para as bibliotecas. Inf. \& Soc.: Est., João Pessoa, v. 17, n. 1, p. 43-51, jan./abr. 2007.

NUNES, J. V. Vivência em rede: uma etnografia das práticas sociais de informação dos usuários de redes sociais na internet. 2014, 307f. Tese (Doutorado em Ciência da Informação) - Programa de Pós-graduação em Ciência da Informação), Faculdade de Filosofia, Ciências, Universidade Estadual Paulista Júlio de Mesquita Filho, UNESP, Marília, 2014.

RECUERO, R.; BASTOS, M.; ZAGO, G. Análise de redes para mídia social. Porto Alegre: Sulina, 2015.

ROCHA, P. J.; MONTARDO, S. P. Netnografia: incursões metodológicas na cibercultura. e-Compós, Porto Alegre, v. 4, 2005. Disponível em: <http://www.compos.org.br/seer/index.php/e-

compos/article/viewArticle/55>. Acesso em: 1 maio 2015. 
SERRANO, D. P. O modelo AIDA. 5 dez. 2008. Disponível em: $<$ http://www.portaldomarketing.com.br/Artigos/0\%20Modelo\%20AIDA.ht m>. Acesso em: 2 maio. 2015.

SILVA, T. Monitoramento de mídias sociais. In: SILVA, T. (Org.). Para entender o monitoramento de mídias sociais. Publicado em 2012. Disponível em: <http://pt.slideshare.net/tarushijio/para-entendermonitoramento-de-midias-sociais>. Acesso em: 6 maio. 2015.

SILVA, T. Métricas e monitoramento em mídias sociais. 2 fev. 2013. Disponível em: <http://pt.slideshare.net/tarushijio/monitoramento-demidias-sociais-imerso-digital? related=1>. Acesso em: 6 maio. 2015.

STRUTZEL, T. Presença digital: estratégias eficazes para posicionar sua marca pessoal ou corporativa na web. Rio de Janeiro: Alta Books, 2015.

TALK2. Novo white paper: monitoramento de mídias sociais. out. 2013. Disponível em: <http://materiais.talk2.com.br/monitoramento_novo>. Acesso em: 6 maio. 2015.

TELLES, A. Redes sociais e mídias sociais: quais as diferenças. 30 mar. 2010. Disponível em: <http://midiassociais.blog.br/2010/03/30/redessociais-e-midias-sociais-quais-as-diferencas/>. Acesso em: 27 jan. 2015.

TERRA, C. F. Usuário-mídia: a relação entre a comunicação organizacional e o conteúdo gerado pelo internauta nas mídias sociais. 207f. 2011. Tese (Doutorado em Ciências da Comunicação) - Programa Pós-graduação em Ciências da Comunicação, Escola de Comunicações e Artes, Universidade de São Paulo, 2011.

VIEIRA, D. V. A adoção de redes sociais em bibliotecas universitárias espanholas: um estudo das aplicações dos resultados da web 2.0. $389 \mathrm{f}$. 2013. Tese (Doutorado em Ciência da Informação) - Programa de Pósgraduação em Ciência da Informação, Faculdade de Ciência da Informação, Universidade de Brasília, 2013. 